\title{
A Comparative Study on Centrality in Museum Layouts - In the Case of the Royal Museum of Scotland and Burrell Gallery
}

\author{
Young Kweon \\ Lecturer, School of Architecture, Kookmin University \\ 861-1 Chongnung-dong, Songbuk-gu, Seoul 136-702 Korea (archeo@korea.com)
}

\begin{abstract}
This study intends to compare the spatial and behavioral patterns of the center space of different museum layouts and interpret them with reference to social contexts. For the study, two Scottish museums were chosen and then examined by using Space Syntax analysis as an analytic framework. Analysis of the two different centralities leads to some fundamental aspects of morphological and cultural implications behind museum layouts. In morphological terms, two types of centrality were unfolded; figured centrality for the Royal Museum of Scotland and spatial centrality for the Burrell Gallery. From the observed result of space use, the two centralities work in the same way; spatially structured centrality was relatively well-used and instrumentalized in people movement while figured centrality did not that was to be symbolized. It led heterogeneity of centrality in cultural implications. Symbolic centrality was represented and crystallized spatial form for social relations and solidarity or even for personal authority, while instrumental centrality was utilized for purely movement and exhibits. Discordance between symbolic and instrumental aspects of centrality seems to be the one of the evidences that presented changing notion since modern architecture of what museum layout is like to be.
\end{abstract}

Keywords: Museum Layout; Centrality; Space Syntax

\section{Introduction}

Architecture is a social art in two senses: in the narrow sense that buildings have social purposes, and in the broader sense that built environments seem to reflect society. Exhibit space in museums in particular, is where the abstract and physical worlds meet. In museums, social knowledge is spatialized intentionally and therefore transmits itself to the public. Peponis and Hedin [1982] pointed out that the museum is a cultural device to transmit knowledge. Museum layouts therefore necessarily imply underlying principles in organizing space to meet specific social requirements. [Choi, 1993; Duncan, 1995; Markus, 1993]

Centrality in museums, in particular, seems to be the key role in expressing such social goals. Chronological study (Choi, 1996) revealed the central space to be the crucial place not only for exhibitions but also sharing collective experience such as visitor interaction. The evolution of society and architecture, and transformation or apparent changes in the characteristics of

Contact Author: Young Kweon, School of Architecture,

Kookmin Univ., 861-1 Chongnung-dong, Songbuk-gu, Seoul

136-702 Korea

Tel: +82-2-910-4266 Fax: +82-2-910-4609

e-mail: archeo@korea.com

(Received October 10, 2001; accepted December 20, 2001) centrality have occured. Different social backgrounds produce different roles for the center space in museum layouts.

This study intends to interpret the way in which center space is working in different museum layouts and furthermore what kind of ideas are embedded in such centrality in museums. To explore this argument, preliminary assessment of the apparent differences of centralities in two different museum layouts is required. Space Syntax [Hillier et al, 1984; Hillier, 1996] has been largely adopted, as a method, to analyze the spatial structure of centrality. Space Syntax analysis pays attention to social relations, and events express themselves through spatial configuration.

The arguments are exemplified and verified through comparative analysis of two distinctive Scottish museums - The Royal Museum of Scotland in Edinburgh and the Burrell Gallery in Glasgow.

\section{Typology of Centrality}

What is center space like? The archetype of center space originated from the architecture of the late eighteenth century museums. [Choi, 1996] It was evident that architectural plans, designed by Boullee, Durand, and Schinkel, characterized center space as a huge rotunda surrounded by a continuous gallery. Such ideas were adopted and rationally elaborated in modern architecture, for example the Guggenheim Museum. It was explicitly very effective in instrumental and 
symbolic terms; huge open space accessible from any direction, uninterrupted visibility, integration of movement, and concordance of the classification of objects. Bennett [1995] argues that, in more sociocultural terms, the rotunda type (Bennett called it the amphitheater type) as center space in museums was a mid nineteenth century invention. It is closely related to the notion of social reformation. The visual openness and transparency in museum space was the architectural setting to celebrate and intensify emerging civil society. Museum-going was no longer a matter of just viewing something curious but the civil-right of self-consciousness and social participation. Even in many other building types in the nineteenth century such as commercial arcades, festival halls, its architectural properties could be found. (Figs. 1 and 2)

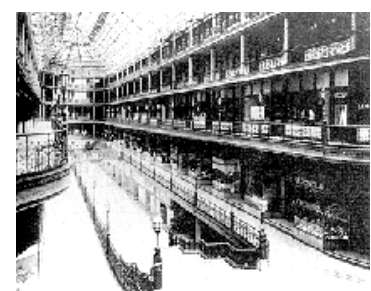

Fig.1. Cleveland Arcade

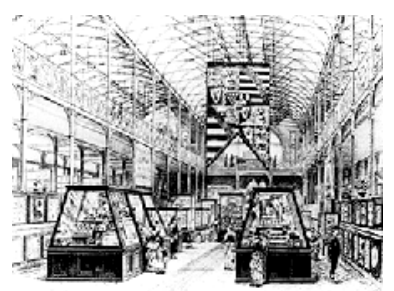

Fig.2. Bethnal Green Museum
Precedent studies share some common properties from which we can induce what center space is. It deciphers center space in museums as follows.

(1) Figured property; huge open space that is of a relatively simple geometrical shape.

(2) Principal function: main exhibit or place for main functions in a building.

(3) Spatial configuration; principal place in a museum which is easily accessible from any other place in it.

(4) Visual transparency; open visual field that penetrates to the other relevant areas.

(5) Social interaction; place to make events for the conscious collective experience of museum-goers.

Centrality is a conceptual framework that involves above all a mixture of each definition of center space. Interpretation of centrality is the key to understanding the way in which museum layout works. Changing centrality is not simply about formal transition in museum architecture but changes in exhibit principles that are associated with social transition.

The present paper presupposes, in particular, a relation between centrality as a built form and behavior mediated by spatial configuration. The ideas behind centrality can also be fully discovered by comparative studies between different museum layouts that have different architectural settings and backgrounds. Interpretations of centrality will be exemplified through appropriate examples.

\section{The Samples}

First of all, comparison by chronological classification of museum architecture can be considered.
Different historic backgrounds seem to be one of the key agents that involve different architectural styles and exhibit layout. The purpose of building museums is also analysed. The examples however, should not only share a common cultural foundation but also match in dimension for spatial analysis.

For the study, two Scottish museums have been chosen; the Royal Museum of Scotland in Edinburgh and the Burrell Gallery in Glasgow. Their heterogeneous building history produces quite different architectural settings, even in museum layout. A brief description of the two museums follows.

\section{1) The Royal Museum of Scotland}

The Royal Museum of Scotland (RMS), originated from The Industrial Museum of Scotland and was set up in 1854 by the Board of Trade to incorporate the natural history collections of the University of Edinburgh. The Museum building in Chambers Street (Fig. 3) was designed in the Venetian Renaissance style by Captain Francis Fowke (1823-65), of the Royal Engineers. It is one of the finest examples of Victorian architecture in the country.

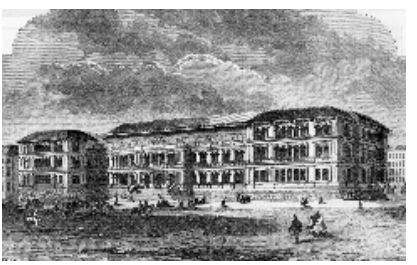

Fig.3. Early design (1823)

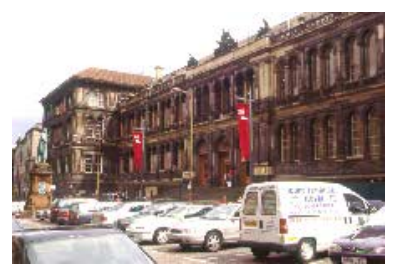

Fig.4. Present RMS Building
Construction of the present building began in the spring of 1861. The east end of the building was completed in 1865 and officially opened on 19 May, 1866 by Prince Alfred. The remainder of the Main Hall and the galleries on the south side were completed by 1874 and the west wing of the building by 1888 . (Fig. 4 )

The RMS illustrates several characteristic features of Victorian architecture. The massive sandstone facade that is retrospective Victorian style contrasts strongly with the modernity and airy lightness of the interior. The huge main hall as a center space characterizes the museum. The main hall on the ground floor functions not only as a vertical circulation path but as a resting place with small fountains and cafeteria. Its large void space draws inevitable form that is the circular gallery on the first and the second floor. (Fig. 5) The galleries on both floors are also accessible not only from the main hall but also from the exhibit areas, especially those for decorative art: Ceramics and Glass on the first floor, and Islam, Japan, China and Middle East collections on the second. Galleries on each floor mediate and distribute visitor movement flow from the main hall into the exhibit area that is a deeper space than the main hall. (the left wing and a part of the right wing of the museum are both temporarily closed for the construction of a new extension) 


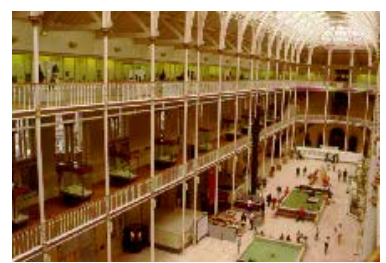

Fig.5. Main Hall, RMS

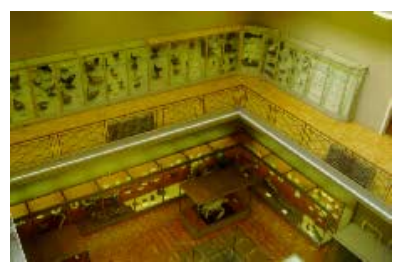

Fig.6. Nature Gallery, RMS
As in the main hall the main exhibition area consists of a circular gallery and void space which extends from the ground level to the roof. (Fig. 6) All exhibition areas are clearly connected to the main hall by the galleries which surround the exhibition areas. Circular galleries in the exhibition areas produce a relatively strong processional movement as the objects are also clearly classified in historical or natural (scientific) order.

The objects on display are quite various; the museum accommodates three main divisions of collection - The Natural World, Decorative Arts, Science and Industry. All categories are roughly placed in separated parts of the building; The Natural World at the left, Decorative Arts in the center and Science and Industry at the right of the museum.

\section{2) Burrell Gallery}

The Burrell Gallery (BG) opened in 1983, in Pollock Park, five miles away from Glasgow city center (Fig. 7). This is one of those few modern buildings which transform clients' wishes and desires as absolute architectural values.

In 1930, the great ship owner Sir William Burrell (1861-1958), decided to create a permanent collection that he could donate to the public. In 1944 he gave his collection of 5,000 artworks to the City of Glasgow, together with the money to build a museum. Burrell was strict in his ruling that the museum must be built in a rural setting away from the polluted city. In 1967, Pollock Park was chosen as a suitable site five miles away from the center of Glasgow. In the meantime Burrell added a further 2,000 works to the collection including a collection of medieval stone doorways and windows. He stipulated that these must be incorporated into the fabric of the museum. [Norwich, 1997] The strict regulations also stipulated that the rooms where Burrell lived in Hutton Castle should be reconstructed and furnished in the museum.

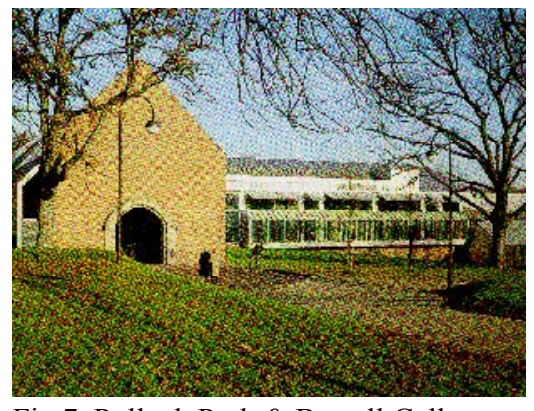

Fig.7. Pollock Park \& Burrell Gallery

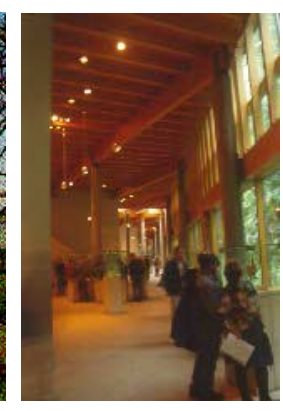

Fig.8. North Gallery
In terms of architectural style, the absence of geometrical unity distinguishes the museum from the other local museums. The BG is a single story building with a small mezzanine. The trapezoidal shape of the building, despite its relatively simple exterior, makes its spatial structure more complex and heterogeneous.

The long glazed north-facing wall, totally shaded by trees, is the key element of the design. (Fig. 8) The great wall on the north side generates a parallel system of glazed and unglazed galleries with the terminal gallery at the west extending to become the entrance court and lobby. The overall trapezoidal shape of the plan seems to guide the visitor around but also offers a choice of routes for the visitor and helps them to know their location whatever route they choose.

Regardless of architectural style or function of the museum, the architect Barry Gasson, resolved the problems posed by the elements of the Collection: incorporation with the three Hutton Rooms, the stone arches and windows, the tapestries and stained glass, the paintings and so on. The solution was to place the rooms out of context. (Fig. 9) The stone arches and windows are also utilized as architectural elemets. Two arches in particular were planned to be together, the outside entry arch and the large portal in the courtyard. Both arches were to be the gateways to the courtyard and to the great hall beyond. (Fig. 10) The other arches have been located for reasons of place or context. The tapestries and stained glass are major elements in the collection. The tapestries required walls without daylight, the stained glass, on the other hand, required bright direct light in the architectural context. The solution was to hang the tapestries in the center galleries of the building where they would be visually related to the woodland edge of the North Gallery, while the stained glass panels have been placed between timber mullions along the south side of the building
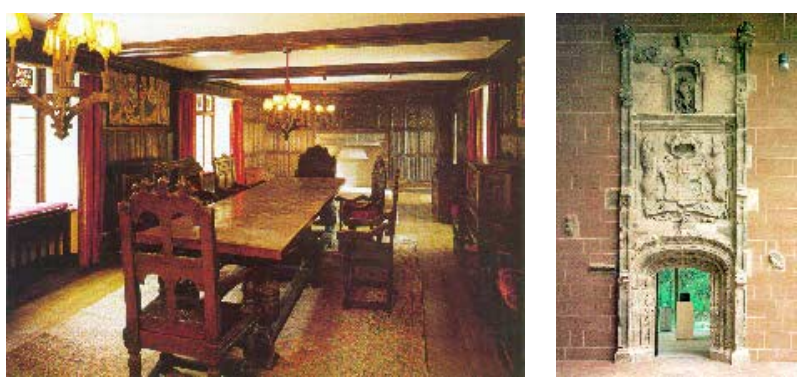

Fig. 9. Hutton Castle Hall, BG

Fig.10. Archstone Portal

The collection is very diverse and heterogeneous. All objects are categorized by six terms; Ancient Civilization, Medieval and Post Medieval European Art, Paintings and Drawings, Oriental Arts, The Hutton Castle Rooms and Period Galleries. A selection of the major pieces is displayed on the primary route facing north woodland. The perimeter is connected by two cross-routes, partly in the form of day-lit galleries, which offer short cuts, aid orientation and enable all parts to be seen as a whole. These local circulation routes cover the entire exhibition area. The mezzanine gallery, which exhibits 15 th century European paintings, 
is accessible from the north exhibition area that displays Ancient Civilization.

\section{Methodology - Space and Space Syntax}

Abstract 'space' is a kind of human artifact. The abstract form is not visible but is represented by using visible things, while space is represented through social behavior, which can be visually quantified. As natural things show a certain regularity, which seems to be dominated by a certain rule, the social behavior also indicates a certain grammar that is believed to control it. Therefore, quantification is crucial to tracing the grammar.

'Space Syntax' (Hillier, 1996, Hillier et al. 1982) is a kind of technique used to identify and analyze space. It describes the layout of space in terms of relational pattern. Such configuration analysis techniques allow a detailed description of any building in terms of the structure of space. Through this method, the complicatedly woven structure of space is simplified and finally revealed.

Using Space Syntax methods, the spatial characteristics of 'centrality' in museum layouts can be traced. This is also accompanied by the conjunction of empirical data - an observational study that analyses visitors' actual movements and behavior. The correlation between Syntactic analysis and observed outcomes are examined using statistical methods (mainly regression analysis). The following descriptions are frameworks of syntactic methodology.

1) Convex Analysis: The convex map shows the fewest and fattest convex spaces that are needed to cover the system. By definition, a convex space is an area, all parts of which are completely available for inspection. Using this method, the spatial centrality of an entire space (not centrality as a geometrical form), which has local meaning (for grouped spaces connected to each other), was revealed through the form of integration and segregation of space. From the purely syntactic point of view, frequent people movement is expected in integrated space while this is not the case with segregated space.

2) Axial Analysis: The axial map indicates the fewest and longest lines that are needed to cover all the convex spaces and make the connections of permeability between them. This method is also about spatial properties, which has global meaning (for the entire building), and is revealed in the form of integration and segregation of space.

3) Visual Fields Analysis: Visual fields represent the visual field which is available from a certain point of space and evaluates the quality of center space in terms of visibility. The meaning of visual fields lies in the way in which visual connections among spaces affect spatial perception.

4) Observation Analysis : All the outcomes of syntactic analysis described above, could be verified observation studies conducted on the inside of an actual building. 'Snapshots of space use', a method of observation, is especially effective in the study of buildings. This method is relevant for recording the static or dynamic use of space in a building, and can also be used to create powerful graphic representation of movement in different areas.

\section{Syntactic Analysis of Museum Layouts}

\section{1) Convex and Axial Analysis}

In the case of RMS, the building consists of a series of convex spaces shaping the large main hall and several small ringy (circularly interconnected) convex spaces. The main hall is void, providing a huge open space vertically visible throughout the three floors. In the $\mathrm{BG}$, all convex spaces are configured like a net.

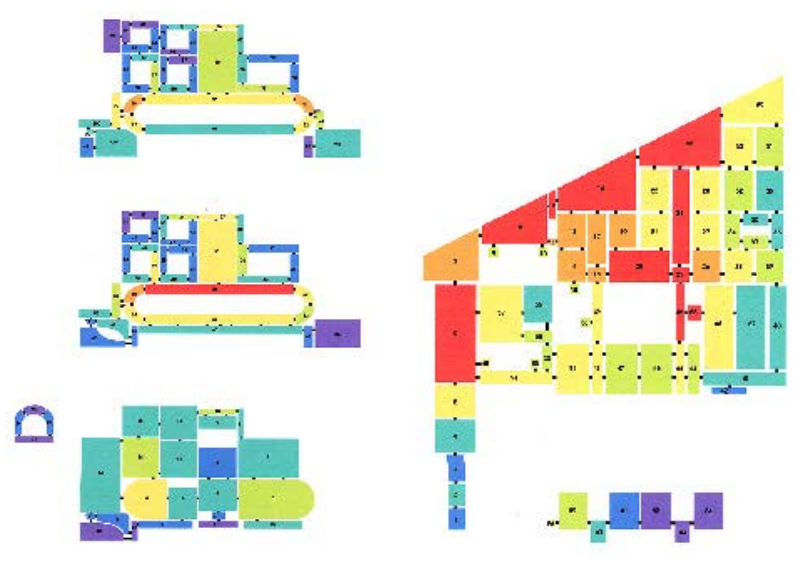

Fig.11. Integration Map (RMS) Fig.12. Integration Map (BG)

In the integration map (Figs. 11 and 12), high integration values in the RMS are highly concentrated in the main hall space in the heart of the museum, the second floor gallery especially is the most integrated space. Meanwhile, the main exhibition area to the north, behind the main hall is mostly segregated (low integrated). The more segregated spaces on each floor are virtually invisible from the main hall and galleries which are mostly integrated space. Nevertheless, in the BG, the most integrated spaces are mainly situated in the main north exhibition area facing the long glazed wall. There is no extremely segregated space on the ground floor of the $\mathrm{BG}$, and all exhibition spaces are relatively integrated compared to the RMS. The most segregated space is located in the mezzanine gallery that is a linear convex sequence allowing only one directional access. In spite of such segregation, the mezzanine does have good visual accessibility and permeability that is associated with the ground floor.

In the convex analysis, the result seems to be quite significant because, in terms of spatial functions, it is expected that those integration spaces are playing a principal role in distributing movement flow inside the individual exhibition rooms. Such a principle function, the movement distribution of space, is one of the key features of center spaces in museums. 
Table 1. Summary of Mean Integration and Intelligibility Values from Convex Analysis

\begin{tabular}{c|c|c|c|c}
\hline \multirow{2}{*}{} & \multicolumn{2}{|c|}{ RMS } & \multicolumn{2}{c}{ BG } \\
\cline { 2 - 5 } & Total & $\begin{array}{c}\text { Main } \\
\text { Hall }\end{array}$ & Total & $\begin{array}{c}\text { North } \\
\text { Gallery }\end{array}$ \\
\hline $\begin{array}{c}\text { Mean } \\
\text { Integration }\end{array}$ & 0.932 & 1.172 & 0.838 & 0.976 \\
\hline $\begin{array}{c}\text { Intelligibility } \\
\left(\mathbf{R}^{\wedge} \mathbf{2}\right)\end{array}$ & 0.448 & 0.631 & 0.239 & 0.429 \\
\hline
\end{tabular}

Scattergrams, which are calculated and represented from convex analysis, result in the intelligibility values of the spatial configuration of the two museums. The intelligibility can be measured by 'analyzing the relation between how a complex can be seen from its parts and what it is like in an overall pattern, that is, as a distribution of integration' [Hillier, 1996]. This is, expressed by a scattergram showing the degree of correlation between the connectivity and integration values of each convex space. In a very narrow sense, the intelligibility can be measured by the R- square value of a scattergram. (Table 1, Figs. 13 and 14)

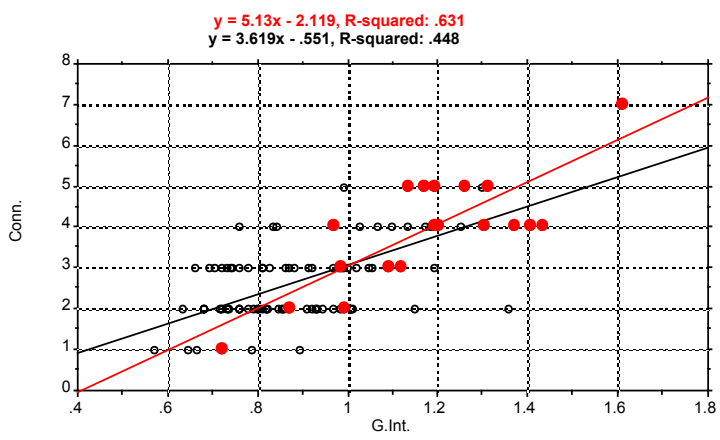

Fig.13. Correlation between Connectivity and Integration from Convex analysis of RMS

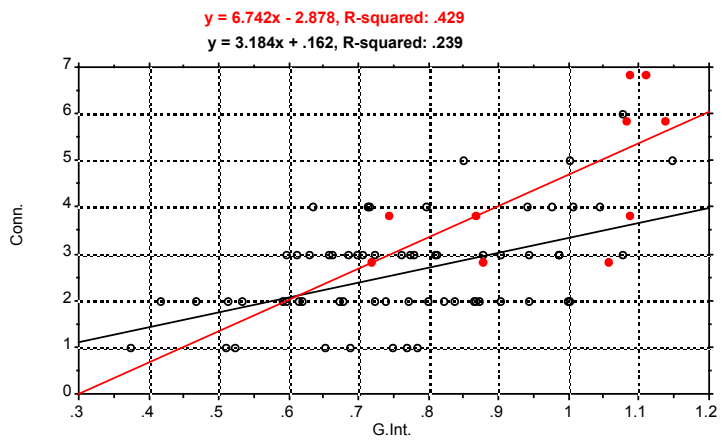

Fig.14. Correlation between Connectivity and Integration from Convex analysis of BG

$\mathrm{R}$-square value in the RMS is much higher than that in the BG by 0.2 . It can be interpreted from this that there is a much stronger correlation between connectivity and integration in the RMS, and that the well-connected system of the RMS in this case, tends to be well-integrated. In general, higher intelligibility means that when we move around the system we will receive good information about the layout as a whole from what we see locally [Hillier, 1996].
Axial analysis shows the same tendency in integration patterns. In the RMS, the most integrated axis can be found on the first floor gallery. In the BG, the most integrated axis does not change, but the overall pattern of the other axis' integration becomes much more segregated compared to the convex analysis. In the axial integration map of the BG, the north exhibition axis is much emphasised. From the axial analysis it is expected that in terms of people movement the north main axial space is more significantly used than the other routes leading to the inside of the building.

\section{2) Visual Fields Analysis}

All visual fields (Figs. 15 and 16) are used in attempting to reveal the visual properties of specific spaces of both museums. One principal axis for the RMS and three for the BG, all those found and induced from the result of convex analysis, were chosen for visual fields analysis. Each visual field was produced by 'axial,' assuming that all visual fields could be drawn from an axial line along with the viewers moving sequence.
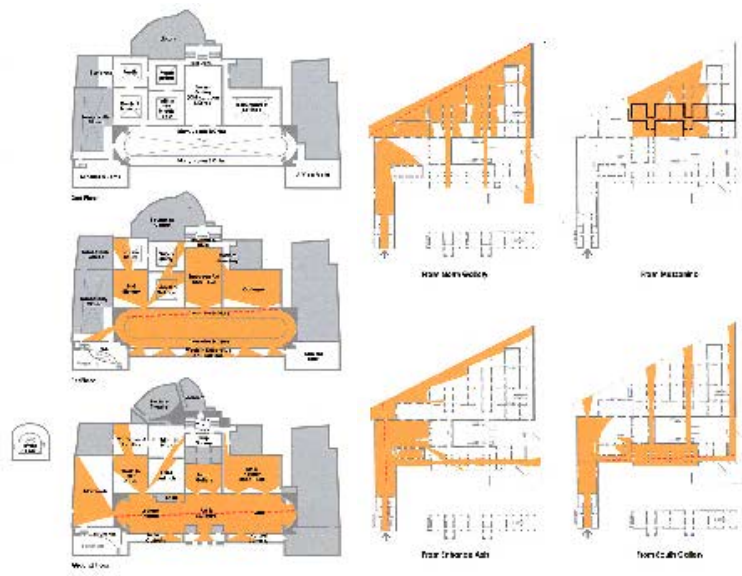

Fig.15. Visual fields (RMS)

Fig.16. Visual fields (BG)

The main hall of the RMS has a very large visual field. However, two sections located in both wing areas (Fish and Minerals and Gems in the left wing, Ancient Egypt and A Wider World in the right wing) are hardly identified by viewers, despite being well-covered by a large visual field from the main hall.

Four visual fields were drawn for the BG; the entrance axis, north gallery main axis, sub axis penetrating the Stained Glass gallery, and the Paintings gallery in the mezzanine. The visitors' orientation can be ascertained in the visual field from the north axis. This visual field would cover virtually the whole exhibition area except the Period Gallery. While the RMS has poor visual fields in some parts, the BG has a quite clear awareness of the main route, even the sub route directly connected to the Stained Glass Gallery in the south. This sort of visual connectivity gives visitors a clear sense of how the museum space is organized and the circulation constructed.

\section{3) Observation Analysis}

From 'snapshot' observation of the RMS (Figs. 17 and 18), it is verified that the ground floor is well used 
by visitors. The main hall is especially dominated by moving rather than standing people, although in the ground floor cafeteria many sitting people were found. The figures reveal the way in which space is intensively used by movement or standing. However, the other spaces are poorly used by visitors, in particular the gallery space on the first and second floor was not as much used for moving and standing as on the ground floor. The graphic representations of movement are irregularly dispersed, and there is no intentional movement and occupying of space. All exhibition areas seem to be rather randomly used.

In BG, (Fig. 19, Fig. 20) a certain regularity of movement was found in some routes; the north gallery and the Stained Glass Gallery, while standing people were found inside the main exhibition area. The number of moving people in the north and south routes seems not to be absolutely dominant in compared to that of standing people. The number of people, who use the area for walking rather than standing and viewing in the north and south galleries, is dominant. In short, even though there are various collections in those areas, people tend to use the space for movement.
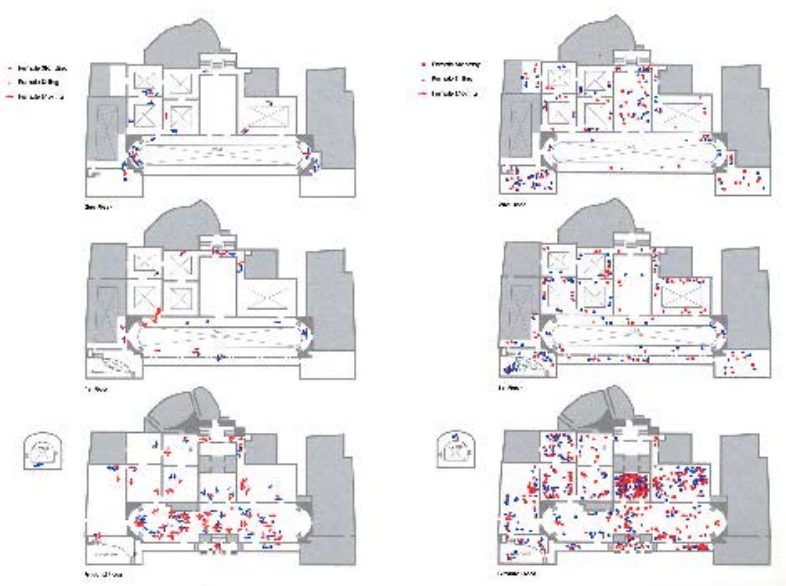

Fig.17. Space Use Snap Shot (Moving) Fig.18. (Standing) for RMS

Unlike the RMS where the core of the building is poorly used both in terms of movement and standing, the mezzanine gallery in the BG is actively used. Some of these areas show much more integrated standing people than any other place in specific time period.
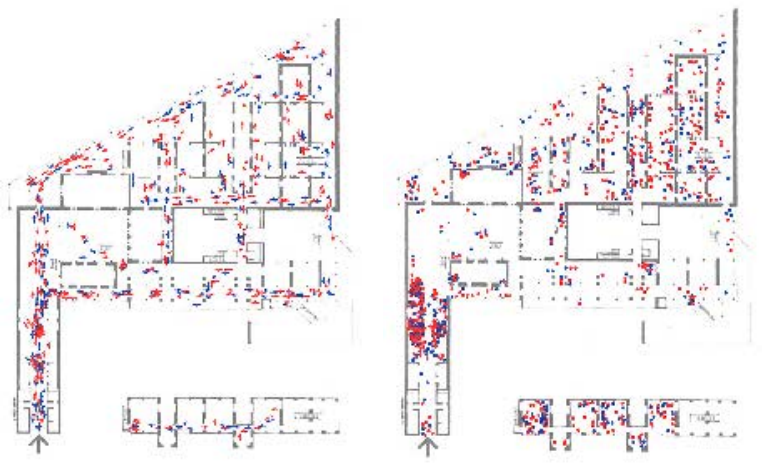

Fig.19. Space Use Snap Shop (Moving) Fig.20. Standing (BG)
However, in both museums, the correlation between observation and integration are poorly correlated with each other (Table 2). It seems that actual behavior in the museums can not be anticipated as in analytic result of spatial configuration.

Table 2. Summary of Correlation Values between Integration and Observation (for whole spaces)

\begin{tabular}{c|c|c}
\hline & RMS & Burrell \\
\hline Correlation (R^2) & 0.028 & $2.016 \mathrm{E}-4$ \\
\hline
\end{tabular}

It can be imagined that there are external factors affecting behavior. In fact, both museums have strong attractive spatial factors; a souvenir shop in the BG and cafeteria in the RMS. Those spaces are not actually exhibition areas, but have been included in the observation because they are accessible to visitors as a part of the public space in the museums. These kinds of attractive factors produce a bias in the observation regardless of the analytic results.

Table 3. Summary of Correlation between Integration and Observation (for center spaces only)

\begin{tabular}{c|c|c}
\hline & RMS & Burrell \\
\hline Correlation (R^2) & 0.455 & 0.348 \\
\hline
\end{tabular}

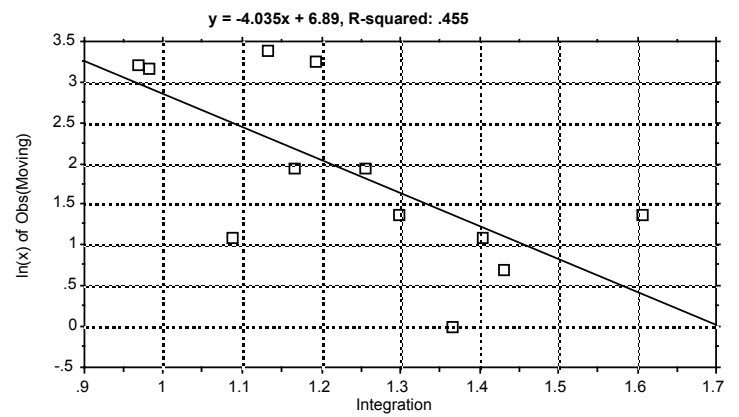

Fig.21. Scattergram for Correlation between Integration and Observation (for center spaces of the RMS only)

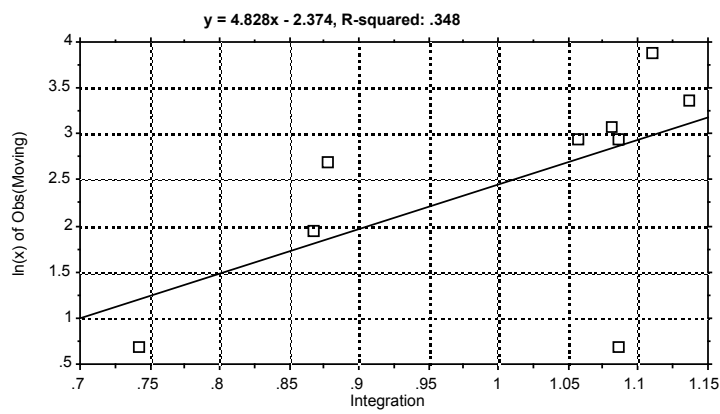

Fig.22. Scattergram for Correlation between Integration and Observation (for center spaces of the BG only)

To avoid this, selective analysis has been conducted. The study therefore assumes that only a few spaces concerning to centrality have been chosen; the main hall with the main circular gallery on each floors for the RMS, and the north gallery space for the BG. (Table 3, 
Figs. 21 and 22) These all have higher integration values than the average. The scattergrams were redrawn and re-examined. No Significant correlation between observation and spatial integration has been represented in the graph. However, the resulting correlation value was more significant than that of the all-space analysis.

The graph for the BG, indicates a clear correlation between, in particular, moving people and integration value, and its value $\left(\mathrm{R}^{\wedge} 2=0.348\right)$ confirms the regular pattern of this correlation. This implies that movement in the principal space concerning centrality is relatively correlated with its spatial configuration.

However, the scattergram for the RMS regression analysis comparing the integration value to the moving people rate indicates an inverse relation, though it has higher intelligibility. People movement does not match with spatial integration, especially in the principal space concerning centrality

\section{Discussion}

From the above analysis, spatial configuration of the center space is a much more effective method of investigating how the system actually works. Space Syntax analysis uncovered the spatial structure of both museums; distribution map of integration, visual fields from specific spaces and graphic representation of space use in reality.

Even if there is no obvious figured center space, presupposition that there should be a 'virtual' center space in the BG is necessary, in order to comparatively investigate how these are working in different museum layouts. 'Virtual' center space has to comply with the definitive principles of the RMS, without figured properties.

\section{1) Morphological Interpretation of Centrality}

How then is the centrality actually working? The outcome of syntactic analysis is in accordance with what was anticipated intuitively from figured centrality of the RMS. The main hall is the highest integrated place in the museum, and in convex and axial analysis of the building, it and the circular galleries are well connected and integrated. It is thus anticipated to be playing a principal role in circulating and distributing people movement on each floor. The visual fields from the center space are large and impressive, and permeable into the exhibition area as well as vertically penetrating the void space in the core of the building.

However, in reality, the center space in the RMS, was poorly used. More precisely, observation analysis; the main hall on the ground floor was the core of high integration movement and standing, while the first and second floor galleries were less dominant in terms of movement. Movement was rather dispersed, and in general irregularly occurred in galleries on each floor. The scattergram revealed that there is a inverserelation between spatial integration and movement in the center space.

While the syntactic properties of the RMS represent an integrated center space where it is not actually used intensively, that of the BG shows high integration of 'virtual' centrality. The north axis as a part of the main global route, covers the entire exhibition area and offers all around visual connection and permeability. Convex and axial analysis shows that the north spaces are both locally and globally integrated. Observation and the scattergram confirm, this showing that many moving people are attracted to the north gallery which is syntactically integrated in spatial structure.

Even though the building form of the BG is not likely to be that which has obvious figures of centrality such as the RMS, and the British Museum, the pattern of visual fields performs in a similar way even to those of museums with rotunda-type centrality. Visual transparency and reciprocal visibility between one and the other is also found in huge void center spaces such as in the main hall of the RMS. However, subtle differences between the two visual properties are uncovered. Visual axis in the RMS was obstructed within the circular galleries, and visual connections did not permeate into the large exhibit area that is in the south side extension.

From the analytic description, a significant mechanism is raised concerning the way in which centralities are working. It is not very likely to be the same sort of centrality in terms of figured properties. In its spatial structure, some syntactic homogeneity has been drawn from the analysis; high connectivity and high integration are shared in common. In terms of space use by visitors however, the RMS is not working well in the center space, especially in galleries on each floor; dominant movement is marginalized and its pattern is irregularly dispersed. While in the BG fairly significant movement is seen through the north axis. A 'virtual' centrality is realized and mechanized that is working well in reality; the movement pattern is more intelligible than that of the RMS. Identical consequences are found in the visual fields analysis. Visual transparency is apparent in the RMS, but does not extend to the other areas except the main hall. Vague visual transparency is identified in the $\mathrm{BG}$, and is permeable to the other areas, even the mezzanine space.

\section{2) Cultural Interpretation of Centrality}

What produces two different centralities? How do we characterize this? What ideas are hidden behind the two heterogeneous centralities? Above all, these questions can be answered by saying that different architectural and social backgrounds demand certain architectural settings; Victorian in architectural style for the RMS, and modern for the BG. A public museum in the case of the RMS, and as a private collection in the case of the BG, and so on.

Both museums are in a sense social reproductions of which society demands a certain quality of space [Hillier, 1996]; the building form of the RMS could be 
thought of as one of the finest examples of architectural production relevant to transparency that was central to nineteenth century social reform [Bennett, 1995]; The Burrell was a purpose-built for a personal collection, and was intended to be planned and arranged appropriately as Sir Burrell wished.

Hillier [1996] pointed out that social reproduction requires symbolic forms of space. At the RMS, the main hall, as a part of the center space has a very strong symbolic centrality while playing a very weak instrumental role. The symbolic form has been realized by a huge void that served for people not only to view and appreciate the collection but also to provide a place to affirm and fascinate their citizenry's co-presence through the visually connected void space. In the nineteenth century, this sort of centrality appears to have been a representation of the museums symbolic function itself.

At the Burrell, 'virtual' center space is properly instrumental, while its symbolic role is inevitably passed on to the other architectural settings. The symbolic form has been reassigned not by the center space of the building but by the actual and extreme reproduction of Sir Burrell's rooms and several arch stones. They are intentionally located in the heart of the building as stipulated by Sir Hutton himself. The building transferred and newly concentrated its symbolic function into the reproduction of these rooms and arch stones. It not only symbolizes but also ritualizes space in the museum [Duncan, 1995]. While public art museums normally consider visitors as citizens who theoretically enjoy equal access to displays, the Hutton Castle Rooms do not allow visitor access. Inaccessibility produced invisible inequality between collector and viewers while the spatial device removed both time and space from these rooms; allowing them to become a perfect part of a ritual as well as myth.

\section{Conclusion}

The study investigated the centrality of two Scottish museums. Two different centralities lead to the fundamental aspect of cultural implications behind museum layouts.

Both are reproduction of social demands. In the RMS, its form and spatial structure is dominated by the symbolic function concerned with the demands of spatial device and transparency regarding social solidarity [Bennett, 1995], while the instrumental role of the center space has been reduced. Therefore its symbolic form was served by the centrality that people share their collective experience and provide a place in which to affirm their citizenry's co-presence through the visually connected void space.

The vague presence of the figured center space, and 'virtual' centrality in the BG indicate a high connectivity and integration that, in the north galleries, is much dominated by its instrumental function. The symbolic role was separated from the center space but re-accommodated in the reproduction of the Hutton Castle Rooms that represent the donator's authority. The discordance between the symbolic and instrumental aspects of centrality seems to be the one of the evidences that uncovered changing notion since modern architecture of what museum layout is like to be.

\section{References}

1) Bennett, T. (1995). The Birth of the Museum: History, Theory, Politics (Culture : Policy and Politics). London, Routledge.

2) Choi, Y. K. (1993). "Cultural Implications of the Spatial Structure of Museum Layouts." Journal of the Architectural Institute of Korea (Design and Planning), Vol. 9 (10), 81-88

3) Choi, Y. K. (1996). "A Chronological Typology of Museum Layouts." Journal of the Architectural Institute of Korea (Design and Planning), Vol.12 (6), 29-37

4) Diamond, R. (1996). An investigation into access in 'universal survey' museums and their use by visitor, focusing on the Louvre in Paris, and the British Museum in London, Unpublished MSc Thesis, University College London.

5) Duncan, C. (1995). Civilizing Rituals : Inside Public Art Museums London, Routledge.

6) Gasson, B. (1986). Spazio e Socita, Vol. 9, Mar: 33-40.

7) Glancey, J. (1984). "Burrell Museum, Glasgow." Architectural Review, Vol. 175, Feb.: 28-37.

8) Hillier, B. (1996). Space is the Machine. London, CUP.

9) Hillier, B. and Hanson, J. (1984). Social Logic of Space Cambridge, CUP.

10) Markus, T. (1987). "Buildings as classifying devices." Environment and Planning B, Vol.14, 467-484.

11) Markus, T. A. (1993). Building and Power: Freedom and Control in the Origin of Modern Building Types. London, Routledge.

12) Norwich, J. J. (1997). The Burrell Collection. Glasgow, Harper Collins.

13) Othman, S. (1987). "The Structure of the Brief for the Burrell Gallery." Environment and Planning B: Planning and Design, Vol.14, 474.

14) Peponis, J. and Hedin, J. (1982). "Spatial Layout of Theories in the Natural History Museum." 9H, 3: 21-25.

15) Williams, A. (1981). A Heritage for Scotland, Scotland's National Museums and Galleries: The Next 25 Years, Committee on National Museums and Galleries in Scotland.

\footnotetext{
i For this paper, "snapshot" observations were conducted in public spaces only. For the RMS on August 24, 25 and the BG on August 6, 7, 1998. The pattern of movement and behaviors of each visitor was recorded on each building plan during an entire day at regular intervals. Each observation was carried out during two working days, from $11 \mathrm{am}$ to $5 \mathrm{pm}$. Two categories of visitor (male and female) were recorded based on three categories of activity; sitting (partially used in this study), standing and moving. Spaces that were inaccessible to visitors during a typical tour, for example areas available for staff only and storage, were not included in this study.
} 